\title{
A rare case of genital labial phylloides tumour
}

\author{
L Mbodi, ${ }^{1}$ (D) NZ Mtshali, ${ }^{2}$ (D) B Phakathi ${ }^{3}$ (D) \\ ${ }^{1}$ Department of Obstetrics and Gynaecology, Charlotte Maxeke Johannesburg Academic Hospital, University of the Witwatersrand, \\ South Africa \\ ${ }^{2}$ Department of Pathology. National Health Laboratory Services, University of the Witwatersrand, South Africa \\ ${ }^{3}$ CMJAH Surgical Breast Unit, Department of Surgery, Charlotte Maxeke Johannesburg Academic Hospital, University of \\ the Witwatersrand, South Africa
}

Corresponding author, email: mlangi2005@yahoo.co.uk

\section{Summary}

Phylloides tumour is an extremely rare fibroepithelial neoplasm, accounting for less than $1 \%$ of breast pathologies. ${ }^{1}$

We report a rare case of primary phylloides tumour arising within the vulva.

\section{Case report}

A 30-year-old nulliparous, HIV negative woman presented at Gynaecology Outpatient Department (GOPD) with a 6-month history of an enlarging labial mass. The mass was associated with mild pain especially when walking and during sexual activity. There was no vaginal bleeding or discharge.

On examination, a 4 x $5 \mathrm{~cm}$ soft, mobile, mass was limited to the right labium majus. There was no skin discoloration or overlying erythema and there were no palpable groin lymph nodes. The Bartholin's gland was not enlarged or tender to palpation. The tumour was suspected to be a labial inclusion cyst.

The location and characteristics of the mass suggested a Bartholin's gland-associated pathology such as an abscess or a cyst. These were clinically eliminated as potential causes for the mass. A remaining possibility was a labial inclusion cyst and the patient was booked for surgical excision of the mass. Under general anaesthesia, the mass was enucleated, and the wound primarily closed. The patient did well postoperatively, was discharged and followed-up for wound care and histology results.

\section{Histopathological findings}

Macroscopically, the specimen comprised of an enucleated, well circumscribed, firm, grey-white single tissue which measured $50 \times 35 \times 20 \mathrm{~mm}$. On section, a white-yellow cut surface with cleft-like spaces resembling a leaf with variable cysts formation was noted. A cyst measuring $15 \mathrm{~mm}$ in maximum diameter was identified. The cyst wall measured $1 \mathrm{~mm}$ in thickness. The tumour's inner wall was smooth with no papillary projections, haemorrhage or necrosis (Figure 1).

The histological assessment revealed a biphasic tumour showing leaf-like fronds projecting into cystic space. The epithelial component had luminal epithelial cells resting on myoepithelial cell layer. The stroma had a variably fibrous appearance with no increase in stromal cellularity or atypia. In addition, there was condensation of stromal cells. There were two (2) mitoses in $10 \mathrm{HPF}$ (high power field). No heterologous elements were seen. The immunohistochemical stains were negative for desmin and smooth muscle actin (SMA) highlighted blood vessels. These findings are shown in (Figure 2). The lesion was present at the inked surgical margins implying inadequate excision. The diagnosis was that of a benign phylloides tumour.

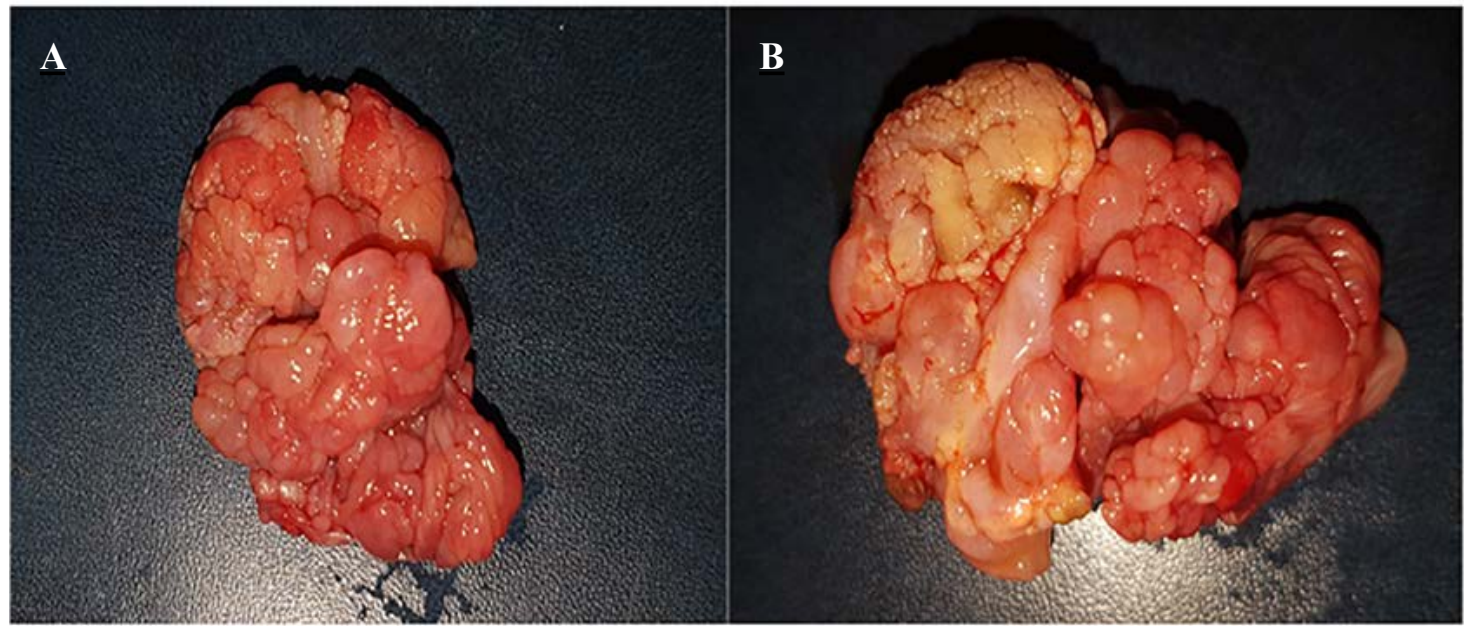

Figure 1: Gross appearance of the tumour at surgery after excision. A: anterior view, B: posterior view of the same tumour 

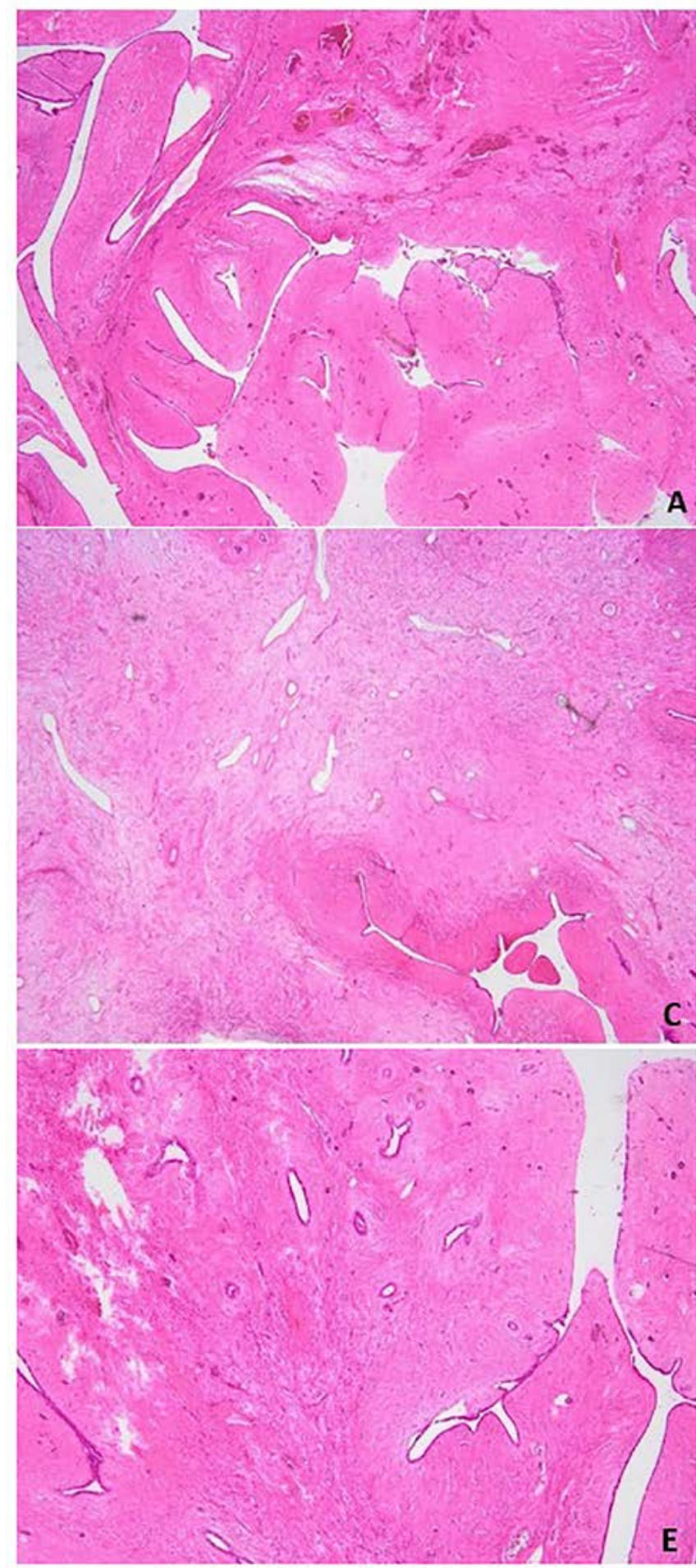

\section{Discussion}

Phylloides tumours are rare fibroepithelial tumours accounting for $0.3-1 \%$ of malignant breast tumours and about $2.5 \%$ of all fibroepithelial lesions of the breast. ${ }^{1}$ They occur most frequently in middle-aged women between the ages of 35 and 55 years, but can appear in adolescents and elderly women. ${ }^{2}$ It is generally accepted that phylloides tumours are typically large, fast growing masses that are formed from the periductal stromal cells of the breast, ${ }^{1}$ although the exact cellular origin of phylloides tumours remains an ongoing debate and the trigger remains unknown. ${ }^{3,4}$

Phylloides tumour of the vulva is an extremely rare entity, and the least common of the differentials for non-acute labial masses. ${ }^{5}$ It most likely occurs in ectopic breast tissue
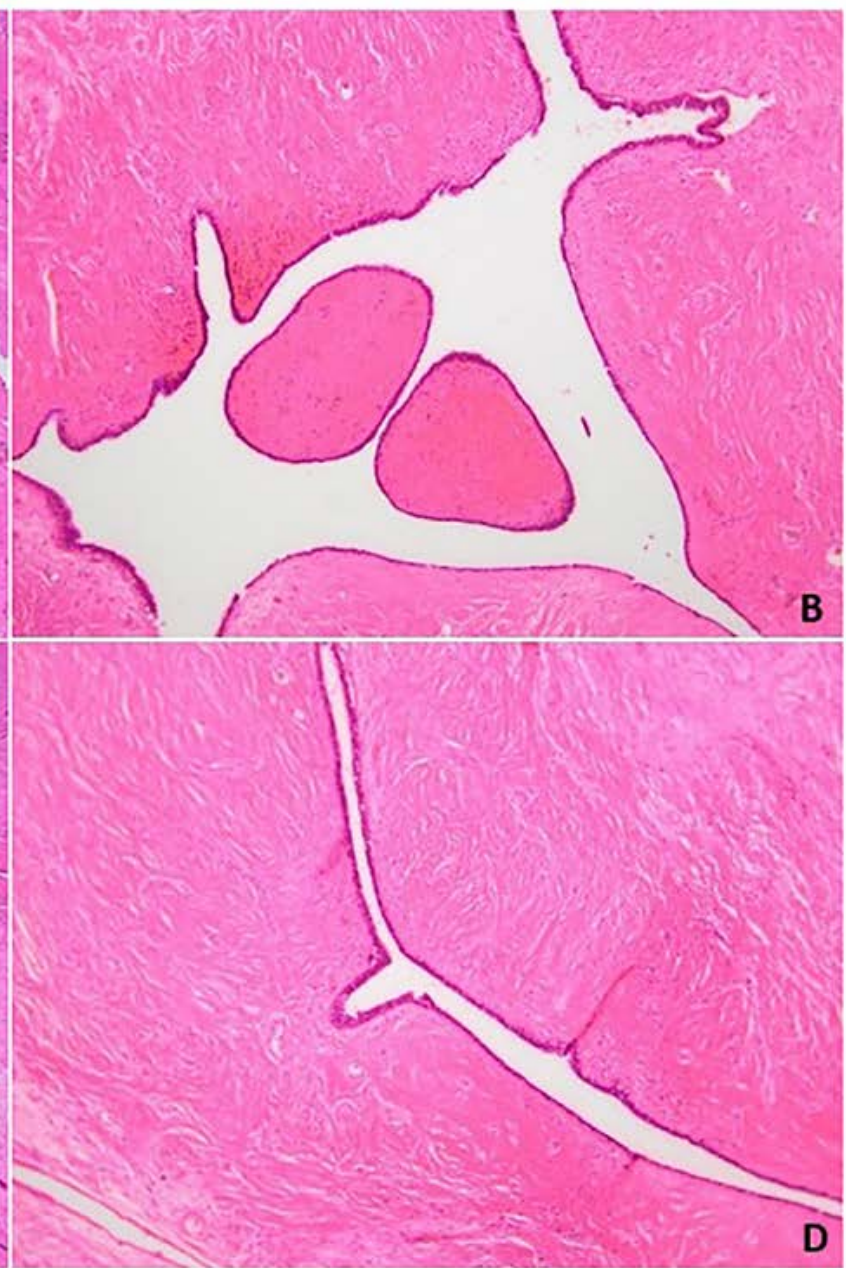

Figure 2: Hematoxylin and eosin images of phylloides tumour of the vulva. A: conspicuous intracellular growth showing leaf-like projections into luminal structures, B: cystically dilated cavity filled with multiple papillary excrescence, $C$ : stromal component showing low cellularity without atypia or mitotic activity, D: minimal cellularity with subtle condensation around ductal epithelium, E: occasional tubular epithelial elements admixed with leaf-like processes

anywhere along the primitive embryonic milk line extending from the axilla to the groin bilaterally, as a result of failure of mammary ridges to regress. ${ }^{6}$ This embryonic milk line can be the site of similar pathological lesions seen in the normal breast. ${ }^{7}$ They are classified as benign, borderline and malignant subgroups based on the degree of stromal cellular atypia and mitotic index.?

The vulval sites are usually the labia majora and minora, but the interlabial sulcus and mons pubis have also been documented. ${ }^{6}$ The patients usually present with a gradually enlarging mass as in our patient, but can also present with a long-standing stable mass. ${ }^{6}$ At present, there is controversy regarding the histological origin of the phylloides tumour of the labia. The debate includes the postulation of ectopic mammary tissue-derived lesions, of cutaneous apocrine 
glands, and mammary-like anogenital glands. In most of the previous medical literature, ectopic mammary tissue theory is favoured because, just like mammary glands, they present hormonal receptors on immunohistochemistry, with the potential of developing benign or malignant processes like those observed in normally located mammary tissue. ${ }^{8}$

The histological features described are similar to that of a breast phylloides tumour. Occasionally, the background feature can be that of higher cellular density composed of larger cells with plump oval nuclei. ${ }^{9}$ Adjacent tissue sometimes shows lobules of mammary-like glands. ${ }^{9}$ A differential diagnosis of an inclusion cyst was made pre-excision. Typically, a histological report of an inclusion cyst will be of squamous epithelium associated with keratin debris. The cysts commonly form secondary to displacement of epithelial fragments after an episiotomy, surgical procedures or trauma of the vulvovaginal region. Grossly, they have luminal keratinous contents that appear "cheese-like". Such was not found on our case, hence ruling out an inclusion cyst.

Immunohistochemistry shows uniformly nuclear staining with oestrogen and progesterone receptor reactivity in the secretory epithelium, with smooth muscle actin and S100 staining in the myoepithelial cells. BRST-2 and mammaglobin exhibit patchy reactivity in the epithelial component. ${ }^{9}$ In our case, the diagnosis of phylloides tumour was made by histopathological classic morphology. The typical clinical presentation in conjunction with a characteristic intraluminal (leaf-like) projections into epithelial-lined cysts on histology prompted a consideration of a phylloides tumour in the differential diagnosis. The use of immunohistochemical stain such as SMA was useful in highlighting the myoepithelial cell layer, whilst the desmin stained the stromal cells. The grading of vulval phylloides is based on the WHO criteria for grading of the breast phylloides tumour.

\section{Management}

Based on the information regarding breast phylloides tumours, a wide local excision with $1 \mathrm{~cm}$ free margin is currently recommended for all histological subtypes of phylloides tumour, as incomplete excision is associated with a 4-fold increased risk for local recurrence, especially for borderline and malignant types. ${ }^{10}$ When the lesion occurs on the labium majus, vulvectomy may be warranted to attain free margins.

There is currently a very limited role for adjuvant chemotherapy and radiation therapy in benign phylloides tumours. ${ }^{11}$ However, adjuvant radiation therapy has been shown to improve the disease-free survival of malignant phylloides tumours of the breast. ${ }^{11}$ In our opinion, the same treatment approach may be adopted for phylloides of the vulva since there are currently no guidelines for their treatment.

Because in our case the patient did not have wide local excision of the labial phylloides, she was counselled on the risk of local recurrence and advised to follow-up 6-monthly for a clinical examination. Unfortunately, she was lost to follow-up.

\section{Conclusion}

Phylloides tumour of the vulva is rare but needs to be taken into consideration as one of the differential diagnosis of vulva lesions. Evidence-based treatment guidelines are needed to guide the management of vulva phylloides tumours.

\section{Conflict of interest}

The authors declare no conflict of interest.

\section{Funding source}

None.

\section{Ethical approval}

Ethical approved was received from the University of the Witwatersrand Human Research Ethics Committee M200275.

\section{ORCID}

L Mbodi (i) https://orcid.org/0000-0002-5950-791X

NZ Mtshali (D) https://orcid.org/0000-0003-0208-4845

B Phakathi (iD https://orcid.org/0000-0002-8991-6060

\section{REFERENCES}

1. Ozbudak HI, Akkaya H, Akkaya B, et al. Phylloides tumour of vulva: report of two cases. Turk Patoloji Derg. 2013;29(1):736. https://doi.org/10.5146/tjpath.2013.01153.

2. Al-Atrooshi SA. Fibroepithelial tumors of female breast: a review of 250 cases of fibroadenomas and phylloides tumors. The Iraqi Postgraduate Medical Journal. 2012;11:140-5.

3. Abe M, Miyata S, Nishimura S, et al. Malignant transformation of breast fibroadenoma to malignant phylloides tumor: longterm outcome of 36 malignant phylloides tumors. Breast Cancer. 2011;18:268-72. https://doi.org/10.1007/s12282-0090185-x.

4. Lightner AL, Shurell E, Dawson N, Omidvar Y, Foster N A single-center experience and review of the literature: 64 cases of phylloides tumors to better understand risk factors and disease management. Am Surg. 2015 Mar;81(3):309-15. PMID: 25760210.

5. Cao L, Chi CH, Ning J, et al. Combination of prostate cancer antigen 3 and prostate-specific antigen improves diagnostic accuracy in men at risk of prostate cancer. Arch Pathol Lab Med. 2018 Sep;142(9):1106-12. https://doi.org/10.5858/ arpa.2017-0185-OA.

6. Ghasoup A, Sadieh O, Mansoor A. A variable presentation of phylloides tumor, case series. Eur J Surg Oncol. 2012;38(9):803-4. https://doi.org/10.1016/j.ejso.2012.06.211

7. Denlinger LN, Lokhandwala PM, Abendroth CS. Benign phylloides tumor of the vulva: a case report and literature review. Rare Tumors. 2015 Dec 30;7(4):6010. https://doi. org/10.4081/rt.2015.6010.

8. Salmo E, Shaw G, Tagore V. Phylloides tumour of the vulva: report of a case and review of the literature. The Internet Journal of Pathology. 2004;4(2). Available from: http://www. ispub.com/IJPA/4/2/12359.

9. De Leon CD, Montiel DP, Vázquez H, et al. Case report: vulvar fibroadenoma: a common neoplasm in an uncommon site. World J Surg Onc. 2009;7:70. https://doi.org/10.1186/14777819-7-70.

10. Lee S, Nodit L. Phylloides tumor of vulva: a brief diagnostic review. Arch Pathol Lab Med. 2014;138:1546-50. https://doi org/10.5858/arpa.2013-0581-RS.

11. Spitaleri G, Toesca A, Botteri E, et al. Breast phylloides tumor: a review of literature and a single centre retrospective series analysis. Crit Rev Oncol Hematol. 2013 Nov;88(2):427-36. https://doi.org/10.1016/j.critrevonc.2013.06.005. 